\title{
Building lifecycle management based on 4D modelling as the main workspace for building risk assessment
}

\author{
$R$ Kazaryan ${ }^{1, *}, N$ Galaeva $^{1}, R$ Avetisyan ${ }^{1}$, and $S h$ Aliev $^{1}$ \\ ${ }^{1}$ Moscow State University of Civil Engineering, 26, Yaroslavskoe shosse, Moscow, 129337, Russia
}

\begin{abstract}
The use of information technology in the management of construction projects has become a decisive factor for the successful completion of projects, taking into account time, quality and financial costs. There are challenges in visualizing the planning process and integrating information between stakeholders. The paper considers some aspects of the development trend of information technology in construction. The element base, including the risks arising during the design and construction, associated with the direct use of computer and mathematical models of the object in the design is considered. The generated information models will provide basic information for the participants in the design process, which ultimately will be the basis of the element base of an effective tool for ensuring project life cycle management. The following methods were used: system analysis, logical-mathematical modelling, systems theory, economic-visual modelling, research methods of operations, economic and mathematical methods. A basic block diagram of 4D modelling is presented to minimize the occurrence of risks during design. The model allows considering the possibility of assessing the duration of the project, the level of labour productivity, as well as visualizing the construction process. The presented analysis indicates the importance of using 4D modelling in relation to the life cycle of the object in order to prevent the possibility of construction risks.
\end{abstract}

\section{Introduction}

In the last decade, the attention of the scientific and professional communities of Russia and leading foreign countries has been focused on the problem of the development of information modelling of construction sector facilities.

Today, a wide range of digital technologies is known (computer and mathematical modelling technologies, technologies associated with Big Data, which allow processing huge amounts of information in a digital field, intelligent technologies that allow determining the position of objects of various facilities in space, cloud servers, intelligent sensors for constant monitoring and surveillance, mobile devices, additive printing technologies). The promotion of information technology is a prerequisite for the development of the construction complex as a digital industry. An attempt is made in the paper to study the main aspects of modern

* Corresponding author: r.kazarian@ mail.ru 
information technologies based on the analysis. The use of digital technologies will allow surveyors, engineers, designers, and architects to work in a single information field and implement complex projects for various purposes. It should be noted that the implementation of digital design methods in practice encounters certain problems (change, retraining of personnel, approaches to solving problems). Such specialists as BIM managers increasingly appear on the labour market (an integral part of digital design). Digitalization of construction and information modelling of objects for various purposes consists in the development and use of coordinated and interdependent design solutions for the subsequent transfer of data for the formation and development of technical documentation [1-2]. The main areas of digital modelling are:

1) A phased transition from the usual information models in three-dimensional space (3D) to higher-level models containing additional data about the object under construction in 4D (time) and 5D (finance);

2) A phased transition of structured engineering information about an object to cloud servers. This approach will greatly facilitate the general use of information.

\section{Methods}

Subcontractors can be involved in the design process, which can significantly increase the likelihood of design risks, with the subsequent transformation of the elements of the finished product quality systems. At the design stages of objects for various purposes, some of the most common risks arise:

1. The likelihood of risks arises already at the first stage, before the design of a capital construction facility begins. These risks are associated with insufficient or low-quality study of the material and information about the future object. At this stage, it is necessary to take into account various factors related to the location of the construction object, the possibility of connecting the object to urban utility services communications, the need to take into account all kinds of urban planning restrictions, transport infrastructure and environmental safety. Only on the basis of reliable information it is possible to make a decision on the terms of reference for the design [3].

2. The likelihood of risks arises when setting goals. A lot of indicators depend on welldeveloped terms of reference (terms of construction and installation works, cost of work, cost of a construction object as a whole). The customer and the general designer must clearly understand the possibility of building an object based on the existing geotechnical base at the construction site, taking into account urban planning restrictions, materials, equipment, engineering systems, etc. In the terms of reference, it is necessary to describe architectural solutions, internal engineering networks, design solutions, a fire safety system, monitoring of load-bearing structures of an object, automation of management of engineering systems and communications [4-6].

3. The likelihood of risks associated with changes in previously made decisions arises at the design stage. During the design process, the customer and the designer have to make decisions that were not worked out in the terms of reference, i.e. make changes to the design documentation. Often, the adjustments made are related to the optimization of design solutions, which make it possible to reduce the cost of construction, increase the efficiency of the work performed without harming the quality and safety of the capital construction facility being built. The adjustments are also related to the crude solutions at the previous stages. It is not unusual that decisions are made that increase both the complexity of their 
implementation and the cost. The terms of development of project documentation and the construction object as a whole are increasing. Incorrect information on engineering and geological surveys may result in changing the previously selected foundation, which entails additional costs (in the absence of appropriate expertise of the geotechnical base, taking into account urban planning restrictions).

\section{Results}

Cost minimization using methods that reduce project risks using some performance criteria at various stages of the object's life cycle are an urgent issue for the construction sector [11$12 ; 13-18]$. The construction of performance criteria can be carried out in three principal areas [13-18].

1. One of the indicators that has a clear dominance over other indicators is taken as a criterion (for example, the time to complete a task or the cost of a project). This criterion is usually called simple.

2. The criterion is formed from two or more indicators by folding them into a composite criterion. The latter, as a rule, has the form of a function, where the relative importance of indicators is not taken into account (they are assumed to be equivalent). An example of such a criterion is the pace of work $V$, which is the ratio of the amount of work $Q$ to the time of their execution $T$.

3. The criterion is formed from $n$ particular criteria $K_{i}$, the relative importance of which can vary. For this, a generalized criterion $K_{o}$ is used.

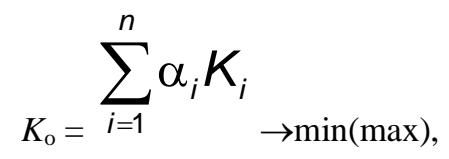

where $\alpha_{\mathrm{i}}$ - weight of each $i$-th criterion $K_{i}$.

The use of digital technologies makes it possible to obtain an accurate model in the digital field, containing the basic geometric parameters and the necessary information about the designed object.

The elements of performance based on the above digital design criteria are:

- $\quad$ Ensuring efficiency in design and minimizing the occurrence of design risks at various stages of construction. The Building Information Model provides the basis for the building risk assessment.

- With the commissioning of the facility, its digital model continues to generate information about the facility on cloud servers. This information will provide operating organizations with monitoring of the safe functioning of engineering systems and communications, bearing structures of the facility.

- A digital model of the facility in three-dimensional space will provide the formation of additional factors of the control element base (time, estimate, etc.).

The schematic diagram required to minimize the occurrence of risks when coordinating projects is shown in figure 1 [7]. 


\section{Discussion}

In each project, there are risks associated with changes in the accepted estimate (budget). A number of risks arise at the stage of approval authorities and state/non-state expertise. Revealed shortcomings and comments left by the approval and expert authorities may require additional deadlines for implementation, and will also entail an increase in the estimated cost of the object.

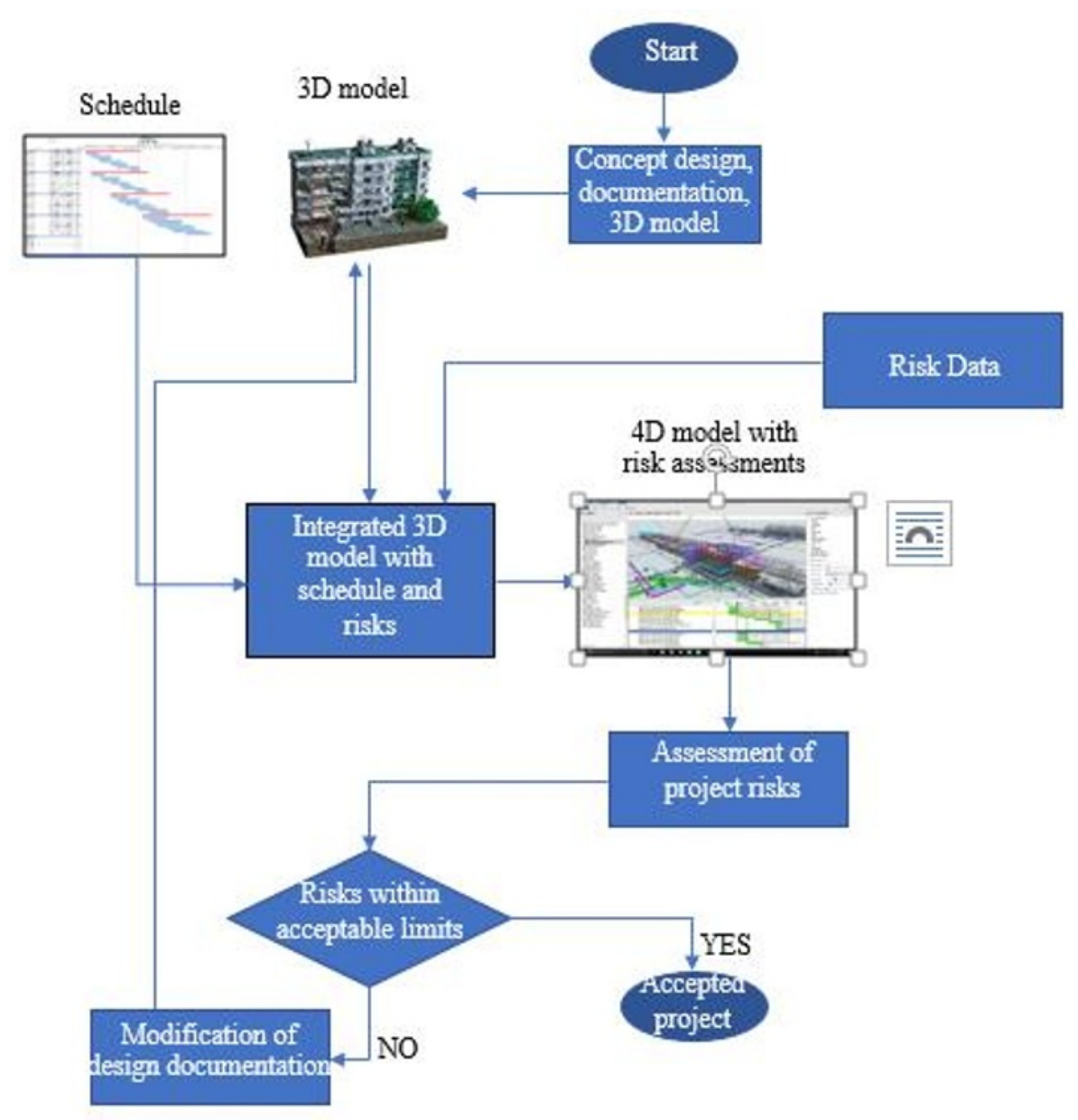

Fig. 1. Block diagram of the considered method.

During the construction of the facility, the likelihood of risks associated with ensuring the safety of the facility during construction and during operation increases. Designers try to minimize or prevent risks using generalized criteria and high-quality materials, adherence to technological processes during construction and installation work. Monitoring of the work of the main bearing structures of the facility, organizational and technological processes of construction is provided. The projects include technogenic, fire-safe and anti-terrorist factors [7-9]. When forming a generalized criterion, it is necessary to solve two problems [13-18]: 
— to determine the significance (weight) of each particular criterion;

— to overcome the 'dimension problem' of particular criteria.

The significance of particular criteria can be established in two ways:

An expert method, the essence of which is described in the mathematical literature. The data obtained is processed by methods of mathematical statistics and some average (or compromise) value is found;

The method of 'relative preference', which is a special case of the expert method (this is the method of one expert - the decision-maker). Its essence comes down to the following actions.

The decision-maker, independently or with the help of colleagues, arranges each of the particular criteria in a row in descending order of their importance. For example, if four particular criteria are used and they are arranged in the order: $\mathrm{K} 1>\mathrm{K} 2=\mathrm{K} 3>\mathrm{K} 4$, this means that $\mathrm{K} 1$ is more important than $\mathrm{K} 2, \mathrm{~K} 2$ is equivalent to $\mathrm{K} 3$, and $\mathrm{K} 3$ is more important than $\mathrm{K} 4$. This is called an 'order relation'. 1. If $\mathrm{K} 1$ is more important than $\mathrm{K} 2(\mathrm{~K} 1>\mathrm{K} 2)$, then the criterion $\mathrm{K} 1$ is assigned a coefficient of importance $\beta 12=3$; 2 . If $\mathrm{K} 1$ is equal to $\mathrm{K} 2$ ( $\mathrm{K} 1=$ $\mathrm{K} 2), \beta 12=2$ is assigned to it; 3 . If $\mathrm{K} 1$ is less important than $\mathrm{K} 2$ (K1 and $\mathrm{K} 2$ ), then $\beta 12=1$.

\section{Conclusions}

Within the framework of the goals and objectives, the following areas of digital technologies can be distinguished to minimize risks at various stages of the object's life cycle:

a) The use of a 4D information model allows controlling the stages of the construction object life cycle, simplifies and optimizes the work of the designer, providing the ability to synchronize the planning process with visualized plans;

b) Using the virtual information space, BIM designers form a single exclusive field for discussion and assessment of construction risks;

c) The use of BIM modelling in the planning of construction projects allows predicting space-time collisions, optimizing organizational and technological processes at the early stages, which ultimately can ensure the profitability of the project.

\section{References}

1. Korabelnikova S and Korabelnikov S 2018 Discussion 93 18-27

2. Churbanov A and Shamara Yu 2018 Vestnik MGSU 13.7(118) 824-835

3. Aleksandrova E 2018 Innovations and Investments 11 15-18

4. Travush V 2018 Construction sciences 3 107-117

5. Azhar S 2017 Procedia Engineering 171 215-226

6. Mesaros P, Spisakova M and Mackova D 2019 IOP Conf. Series: Earth and Environmental Science 222012012

7. Zhao X, Feng Y, Pienaar J and O’Brien D 2017 Architectural Science Review 60(6) 472482

8. Jin Z, Gambatese J, Liu D and Dharmapalan V 2019 Engineering, Construction and Architectural Management https://doi.org/10.1108/ECAM-09-2018-0379

9. Brito D and Ferreira E 2015 Procedia Economics and Finance 21374 - 382 
10. Mahalingam A, Kashyap R and Mahajan C 2010 Automation in construction 19148 159

11. Hartmann T, Gao J and Fischer M 2008 J. Constr. Eng. Manage. DOI: 10.1061/(ASCE)0733-9364(2008)134:10(776)

12. Heesom D and Mahdjoubi L 2004 Construction Management and Economics 22 171182

13. Kazaryan R, Andreeva P and Galaeva N 2020 E3S Web Conf. 15704009

14. Kazaryan R, Andreeva P and Galaeva N 2020 E3S Web Conf. 15704006

15. Kazaryan R, and Andreeva P 2020 IOP Conference Series: Materials Science and Engineering 753(3) 042038

16. Kazaryan R and Pogodin D 2020 IOP Conference Series: Materials Science and Engineering 753(2) 032029

17. Chulkov V and Kazaryan R 2020 Advances in Economics, Business and Management Research 138 371-376

18. Chulkov V, Kazaryan R and Shatrova A 2020 Journal of mechanics of continua and mathematical sciences 8 144-154 